\title{
A retrospective analysis of commonly prescribed medications and the risk of developing breast cancer related lymphedema
} \author{
Padera $^{1-3 *}$ \\ ${ }^{1}$ Edwin L. Steele Laboratories for Tumor Biology, Massachusetts General Hospital, Boston, Massachusetts 02114, USA \\ ${ }^{2}$ Department of Radiation Oncology, Massachusetts General Hospital Cancer Center, Boston, Massachusetts 02114, USA \\ ${ }^{3}$ Harvard Medical School, Boston, Massachusetts 02115, USA \\ ${ }^{4}$ Trinity Life Sciences, Waltham, Massachusetts 02451, USA
}

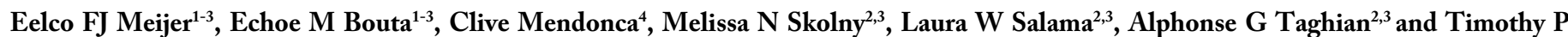

\begin{abstract}
Objectives: Breast cancer related lymphedema (BCRL) is a common complication of current breast cancer treatment modalities, significantly lowering quality of life for these patients and often leading to recurrent infections. Here, based on pre-clinical literature, we aim to retrospectively evaluate the risks of prescribed medications on BCRL development.

Methods: All post-operative breast cancer patients who received radiotherapy from 2005-2013 at Massachusetts General Hospital and developed lymphedema(n=115) were included in the analysis. Comparable patients without lymphedema( $n=230)$ were randomly selected as control. The following classes of medications were analyzed: NSAIDs, corticosteroids, angiotensin system inhibitors, calcium channel blockers and hormonal therapy. Known risk factors for lymphedema development were included as variables, including BMI, age at diagnosis, type of surgery, number of lymph nodes removed and radiation therapy. Outcomes were BCRL development and lymphedema severity.

Results: Similarly, to previous studies, we found that an increase in BMI increases the risk of BCRL(p=0.006) and axillary lymph node dissection has a higher risk of developing BCRL compared to sentinel lymph node biopsy(p=0.045). None of the drugs studied increased the risk of BCRL development or lymphedema severity. However, lymphedema severity was positively correlated with the number of lymph nodes removed $(\mathrm{p}=0.034)$.

Conclusion: We found that anti-inflammatory drugs, anti-hypertensive drugs and hormonal therapy taken during the year postoperatively do not increase the risk of BCRL development or lymphedema severity in breast cancer patients. While others have demonstrated that the number of lymph nodes removed during surgery increases the risk of BCRL, we found it also correlates to lymphedema severity.
\end{abstract}

\begin{abstract}
Abbreviations: ACE: Angiotensin converting enzyme; ALND: Axillary lymph node dissection; ARB: Angiotensin receptor blocker; ASI: Angiotensin system inhibitor; BCRL: Breast cancer related lymphedema; BMI: Body mass index; CCB: Calcium channel blocker; NSAID: Non-steroidal anti- inflammatory drug; RLNR: Regional lymph node radiation; RVC: Relative volume change; SERM: Selective estrogen receptor modulator; SLNB: Sentinel lymph node biopsy; TGF: Transforming growth factor, BC: Breast cancer.
\end{abstract}

\section{Introduction}

Over a million women are diagnosed annually with breast cancer worldwide, accounting for approximately a quarter of all diagnosed cancers in women $[1,2]$. These women subsequently undergo treatment that can entail a combination of surgical intervention, radiation therapy, chemotherapy, hormonal therapy and/or targeted therapy. The five year survival rate for stages of breast cancer from carcinoma in situ thru invasive cancer, is now around 90\% [1]. For these patients, lymphedema of the upper extremity is one of the most well-known long-term complications of surgical intervention, including axillary lymph node dissection (ALND) and/or sentinel lymph node biopsy (SLNB) [3]. Depending on the postoperative treatments, the incidence of breast cancer related lymphedema (BCRL) has been reported to range between $2 \%$ and $56 \%$, significantly lowering quality of life and increasing the risk of skin and soft tissue infections (SSTIs) in these patients $[2,4]$.

Lymphedema consists of interstitial accumulation of protein-rich fluid combined with inflammation, adipose tissue hypertrophy and progressive fibrosis [5]. Lymphedema can lead to functional impairment, physical deformity and SSTIs of the affected limbs. It is estimated that there are 10 million patients in the United States currently afflicted with lymphedema [6-8]. Of these it is estimated that over seven million meet the criteria for BCRL. Known major risk factors for BCRL include

${ }^{*}$ Correspondence to: Timothy P. Padera, PhD. Associate Professor of Radiation Oncology, Harvard Medical School, Massachusetts General Hospital. Radiation Oncology- Cox 7, 100 Blossom St., Boston, MA 02114, USA, Tel: 617-643-6920; Fax: 617-724-5841; E-mail: tpadera@steele.mgh.harvard.edu

Key words: BCRL, breast cancer, lymphedema, severity, treatment

Received: February 20, 2020; Accepted: February 26, 2020; Published: February 28,2020 
high body mass index (BMI), radiation therapy, a greater number of lymph nodes removed during surgery, the location of removed lymph nodes and high blood pressure [9]. Current treatments may ameliorate symptoms in these patients, but there is no curative therapy known. Identifying preventative measures and therapeutic options for these patients will improve quality of life for millions of patients worldwide.

Adjuvant radiation therapy following lumpectomy has been shown to reduce the risk of in-breast recurrence and metastasis [10-12] and overall survival [13]. However, radiation therapy has been repeatedly confirmed as a risk factor in the development of BCRL $[14,15]$. In the study from Warren, et al. [11], the lymphedema risk in patients, defined as $10 \%$ arm volume difference, increased from $3-7 \%$ to $21-24 \%$ with the addition of regional lymph node radiation. Unfortunately, little is known about the mechanisms responsible for this effect. Previous studies have shown that VEGF-C sensitizes lymphatic endothelial cells to a state of radiation induced permanent senescence [16], potentially limiting reparative lymphangiogenesis. Further, radiation therapy is known to cause tissue fibrosis-a hallmark of lymphedema-as a result of transforming growth factor (TGF)- $\beta$-dependent mechanisms $[17,18]$. Fibrosis is also a critical inhibitor of lymphatic regeneration [19] and TGF- $\beta$ has been shown to inhibit lymphatic vessel formation $[7,20,21]$.

The effects of angiotensin receptor blockers (ARBs) on TGF- $\beta$ driven fibrosis have been studied in various pathologies [22-25], demonstrating promising results in reducing fibrosis in many different tissues. Angiotensin converting enzyme (ACE) inhibitors have been shown to have similar, but lesser, anti-fibrotic effects [26]. Even though previous studies have shown that fibrosis reduces the functional regeneration of lymphatics, a literature search for the effects of ARBs or ACE inhibitors (together angiotensin system inhibitors, ASIs) on lymphedema and/or fibrosis after breast cancer treatment in humans yielded no results, motivating this retrospective study.

Other therapies could also hypothetically affect the development of BCRL. Inflammation is a hallmark of lymphedema, and non-steroidal anti-inflammatory drugs (NSAIDs), including aspirin, exert their antiinflammatory effects through COX-2 inhibition [27]. Pre-clinically, COX-2 specific inhibition has been shown to restore lymphatic contractility depressed by the inflammatory cytokine IL- $1 \beta$ in rats [28]. In addition, various other circulating inflammatory mediators are known to modulate lymphatic function [29]. Medication prescribed for hormone positive disease in breast cancer patients and steroids have also shown anti-inflammatory and anti-fibrotic effects [30-32]. Moreover, some forms of primary lymphedema are known to develop at or shortly after the onset of puberty [5], suggesting possible hormonal influences on developing lymphedema in these patients. Calcium channel blockers (CCBs), used to treat hypertension in patients, have also been shown in animal studies to inhibit lymphatic function [33].

Based on potential drug interactions with lymphatic vessel function defined by preclinical literature, our aim was to retrospectively evaluate the effects of prescribed medication on BCRL development in 115 patients who underwent breast cancer surgery in the years 2005-2013 and received postoperative follow- up at Massachusetts General Hospital. Finding a differential risk for BCRL associated with prescribed medications could have a major clinical impact by reducing morbidity in millions of patients worldwide and reducing healthcare costs in battling this dreaded, yet common, complication of current breast cancer treatment modalities. Below we describe our retrospective analysis on the above-mentioned medication classes and their potential effect on developing BCRL.

\section{Methods}

\section{Patient Population}

After the approval from the Massachusetts General Hospital's Institutional Review Board, anonymous data were retrospectively collected from medical records of breast cancer patients that underwent surgery between 2005-2013 at our institution. The patients in our study were closely monitored for lymphedema and participated in a screening program [34] with follow-up until 2015. From the 811 breast cancer patients without lymphedema, 230 were randomly selected to be included. All patients with lymphedema $(n=115)$, defined as having a relative volume change (RVC) $\geq 10 \%$ of the arm, were included [35]. Data retrieved from the medical records were BCRL development, severity of lymphedema measured by RVC, and known risk factors for BCRL development: BMI, type of surgery, number of lymph nodes removed and radiation therapy (Table 1). RVC was calculated using perometry, a volume measurement technique utilizing an array of moving optoelectronic infrared sensors. Every patient had their arm measured pre-operatively (baseline arm measurement) and postoperatively, concurrently with chemotherapy infusions or radiation therapy and then at 3-7 months intervals following treatment. RVC reported here is the average of the last 6 months of follow up in the BCRL patients. BMI was measured pre-operatively.

Table 1. Clinical characteristics of patient cohort

\begin{tabular}{|c|c|c|}
\hline & Mean (range) & n (\%) \\
\hline BCRL & & 115 \\
\hline RVC in BCRL (N=115) & $10.5(-6.25-45.02)$ & \\
\hline BMI & $28.0(17.04-55.67)$ & \\
\hline Age at $\mathrm{BC}$ diagnosis & $56.9(24-86)$ & \\
\hline \begin{tabular}{|l|}
$\begin{array}{l}\text { Months to BCRL } \\
\text { development }\end{array}$ \\
\end{tabular} & $15.3(1.71-83.87)$ & \\
\hline \multicolumn{3}{|l|}{ Surgical technique } \\
\hline Lumpectomy & & $236(68.4 \%)$ \\
\hline Mastectomy & & $109(31.6 \%)$ \\
\hline \multicolumn{3}{|l|}{ Axillary surgery } \\
\hline None & & $37(10.7 \%)$ \\
\hline SLNB & & $199(57.7 \%)$ \\
\hline ALND & & $109(31.6 \%)$ \\
\hline Number of LNs removed & $6.6(0-34)$ & \\
\hline \multicolumn{3}{|l|}{ Radiation therapy } \\
\hline None & & $66(19.2 \%)$ \\
\hline $\begin{array}{l}\text { Partial or total breast } \\
\text { irradiation }\end{array}$ & & $183(53.0 \%)$ \\
\hline $\begin{array}{l}\text { Total breast + subclavicular } \\
\text { and/or axillary irradiation } \\
(\mathrm{RLNR})\end{array}$ & & $96(27.8 \%)$ \\
\hline Adjuvant chemotherapy & & $138(40.0 \%)$ \\
\hline \begin{tabular}{|l|} 
Neoadjuvant \\
chemotherapy
\end{tabular} & & $40(11.6 \%)$ \\
\hline NSAIDs & & $33(9.6 \%)$ \\
\hline Calcium channel blockers & & $20(5.8 \%)$ \\
\hline Steroids & & $2(0.6 \%)$ \\
\hline Aspirin & & $59(17.1 \%)$ \\
\hline $\begin{array}{l}\text { Angiotensin system } \\
\text { inhibitors }\end{array}$ & & $63(18.3 \%)$ \\
\hline \multicolumn{3}{|l|}{ Hormone therapy } \\
\hline None & & $97(28.2 \%)$ \\
\hline SERMs & & $116(33.7 \%)$ \\
\hline Aromatase inhibitors & & $131(38.1 \%)$ \\
\hline
\end{tabular}

BCRL: breast cancer related lymphedema; RVC: relative volume change; BMI: body mass index; LNs: lymph nodes; NSAIDs: Nonsteroidal anti-inflammatory drugs; SERMs: selective estrogen receptor modulators. 
In addition to the known risk factors of BCRL, drug usage of the following was recorded: NSAIDs, corticosteroids, aspirin, ASIs, CCBs and hormonal therapy (Table 2). Only medications initiated before surgery and taken for at least 1 year postoperatively were included. Hormonal therapy was generally initiated within 4 months after surgery and was also included. If patients switched hormonal therapy within a year postoperatively, we included the longest used drug, which was always the second drug in this cohort. We did not look at the effects of drugs initiated after lymphedema diagnosis.

\section{Statistical Analysis}

Data was analyzed using IBM SPSS Statistics v22.0. Univariate analysis was performed using a chi- square or Fisher's exact test for all categorical variables, or a two-tailed t-test. Multivariable logistic regression was used to assess the risk factors for developing BCRL. Multiple regression was used to determine if the RVC, a quantified metric for severity of BCRL, can be predicted by any of the hypothesized risk factors.

\section{Results}

\section{Patient Population}

Out of the 345 patients in this study, the average BMI from 342 patients was $28.0 \pm 6.0 \mathrm{~kg} / \mathrm{m}^{2}$ (mean \pm standard deviation) and age at breast cancer diagnosis was $56.9 \pm 11.8$ (Table 1). Among the total patient population, 199 patients $(57.7 \%)$ received SLNB versus 109 (31.6\%) undergoing ALND. The other 37 patients (10.7\%) did not undergo SLNB or ALND. The average number of lymph nodes removed during ALND was $6.6 \pm 8.1$. The majority of patients $(80.9 \%)$ received radiation therapy, with $183(53 \%)$ receiving partial or total breast irradiation and $96(27.8 \%)$ receiving regional lymph node radiation (RLNR). In patients with BCRL, the mean RVC was $10.5 \pm 9.0$.

\section{Univariate Analysis}

Univariate analysis revealed a significant difference in the frequency of BCRL based on patient BMI at the time of surgery, axillary surgery performed, the number of lymph nodes removed, the use of radiation therapy, neoadjuvant and adjuvant chemotherapy treatment, and the use of ASIs (Table 3). BCRL patients had a significantly higher BMI and a greater number of lymph nodes removed than patients without lymphedema $(\mathrm{p}<0.001)$. A significantly higher rate of ALND and lower rate of SLNB procedures were noted in BCRL patients compared to patients without lymphedema $(\mathrm{p}<0.001)$. There was a greater proportion of patients taking ASIs in the BCRL group (24.3\%) when compared to those who did not develop BCRL (15.2\%).

\section{Multivariable Analysis}

Our results show that an increase in BMI increases the risk of BCRL (Table 4). In addition, our results show that SLNB has a $72 \%$ lower risk

Table 2. List of drugs in each category

\begin{tabular}{|c|c|c|c|c|}
\hline ASIs & CCBs & Corticosteroids & $\begin{array}{c}\text { Hormonal } \\
\text { therapy }\end{array}$ & NSAIDs \\
\hline Valsartan & Amlodipine & Prednisone & Anastrozole & Aspirin \\
\hline Losartan & Nifedipine & Dexamethasone & Tamoxifen & Ibuprofen \\
\hline Irbesartan & Felodipine & & Letrozole & Naproxen \\
\hline Olmesartan & Diltiazem & & Exemestane & Celecoxib \\
\hline Azilsartan & & & Toremifene & Meloxicam \\
\hline & & & Raloxifene & Sulindac \\
\hline
\end{tabular}

ASI: Angiotensin system inhibitor; CCB: Calcium channel blocker; NSAID: Non-steroidal anti- inflammatory drug.
Table 3. Univariate analysis for BCRL risk factors

\begin{tabular}{|c|c|c|c|}
\hline & \multicolumn{2}{|c|}{ Mean (SD) or n (\%) } & \multirow[b]{2}{*}{ Overall p-value } \\
\hline & BCRL & No BCRL & \\
\hline BCRL & $115(33.3 \%)$ & $230(66.7 \%)$ & - \\
\hline BMI & $29.8(5.89)$ & $27.1(5.68)$ & $<0.001^{\&}$ \\
\hline Age at $\mathrm{BC}$ diagnosis & $57.89(11.31)$ & $56.38(11.98)$ & $0.254^{\&}$ \\
\hline \multicolumn{4}{|l|}{ Surgical technique } \\
\hline Lumpectomy & $73(63.5 \%)$ & $163(70.9 \%)$ & \multirow{2}{*}{$0.164^{\wedge}$} \\
\hline Mastectomy & $42(36.5 \%)$ & $67(29.1 \%)$ & \\
\hline \multicolumn{4}{|l|}{ Axillary surgery } \\
\hline None & $8(7.0 \%)$ & $29(12.6 \%)$ & \\
\hline SLNB & $36(31.3 \%)$ & $163(70.9 \%)^{*}$ & \multirow{2}{*}{$<0.001^{\wedge}$} \\
\hline ALND & $71(61.7 \%)$ & $38(16.5 \%)^{*}$ & \\
\hline Number of LNs removed & $11.57(9.56)$ & $4.41(5.83)$ & $<0.001^{\&}$ \\
\hline \multicolumn{4}{|l|}{ Radiation therapy } \\
\hline None & $13(11.3 \%)$ & $53(23.0 \%)^{*}$ & \\
\hline Partial or total breast irradiation & $41(35.7 \%)$ & $142(61.7 \%)^{*}$ & \multirow[b]{2}{*}{$<0.001^{\wedge}$} \\
\hline $\begin{array}{l}\text { Total breast + subclavicular and/ } \\
\text { or axillary irradiation (RLNR) }\end{array}$ & $61(53.0 \%)$ & $35(15.2 \%)^{*}$ & \\
\hline Adjuvant chemotherapy & $61(53 \%)$ & $77(33.5 \%)$ & $.0004^{\&}$ \\
\hline Neoadjuvant chemotherapy & $20(17.4 \%)$ & $20(8.7 \%)$ & $.017^{\&}$ \\
\hline NSAIDs & $11(9.6 \%)$ & $22(9.6 \%)$ & $1.000^{\&}$ \\
\hline Calcium channel blockers & $7(6.1 \%)$ & $13(5.7 \%)$ & $0.871^{\&}$ \\
\hline Steroids & $2(1.7 \%)$ & $0(0 \%)$ & $0.11^{\#}$ \\
\hline Aspirin & $24(20.9 \%)$ & $35(15.2 \%)$ & $0.189^{\&}$ \\
\hline Angiotensin System inhibitors & $28(24.3 \%)$ & $35(15.2 \%)$ & $0.039^{\&}$ \\
\hline \multicolumn{4}{|l|}{ Hormone therapy } \\
\hline None & $25(21.9 \%)$ & $72(31.3 \%)$ & \\
\hline SERMs & $36(31.6 \%)$ & $80(34.8 \%)$ & \multirow{2}{*}{$0.056^{\wedge}$} \\
\hline Aromatase inhibitors & $53(46.5 \%)$ & $78(33.9 \%)^{*}$ & \\
\hline
\end{tabular}

Significant $(p<0.05)$ differences using univariate analysis in the frequency of BCRL based on patient BMI at the time of surgery, axillary surgery performed, the number of lymph nodes removed, the use of radiation therapy, neoadjuvant and adjuvant chemotherapy treatment, and the use of ASIs.

Overall p-value for category from a ^ chi-square, "fisher's exact test, or \&two-tailed t-test; *frequencies significant $(\mathrm{p}<0.05)$ by a $\mathrm{z}$-test. BCRL: breast cancer related lymphedema; BMI: body mass index; SLNB: Sentinel lymph node biopsy; ALND: Axillary lymph node dissection; LNs: lymph nodes; RLNR: Regional lymph node radiation; NSAIDs: Nonsteroidal anti-inflammatory drugs; SERMs: selective estrogen receptor modulators.

of developing BCRL versus ALND. Due to sample size limitations, a selection of variables was included for analysis. None of the drugs studied were statistically significant in our logistic regression analysis, leading us to conclude that use of the selected drugs does not affect the formation BCRL. Using additional multiple regression analysis, the only significant predictor of RVC was the number of lymph nodes removed (coefficient $=0.36, p=0.034$, plotted as a univariate in Figure 1 ).

\section{Discussion}

While univariate analysis showed that several risk factors were statistically related to the frequency of BCRL, only BMI and the axillary surgery were found statistically significant in the multivariable analysis. These data further confirm that ALND [36-38] and BMI [39-42] are risk factors for developing BCRL (Table 4). In addition, we found that several parameters considered known risk factors for BCRL, such as regional radiation therapy and number of lymph nodes removed, were not statistically significant in our sample population (Table 4).

In our cohort, univariate analysis showed a significantly higher proportion of patients with lymphedema received radiotherapy or RLNR, which targeted the supraclavicular and axillary regions. There was a greater proportion of patients taking ASIs in the BCRL group (24.3\%) when compared to those who did not develop BCRL (15.2\%), 
Table 4. Multivariable analysis for BCRL risk factors

\begin{tabular}{|c|c|c|c|c|}
\hline & Coefficient & Standard Error & $\mathbf{p}$ & Odds Ratio \\
\hline BMI & 0.065 & 0.024 & $0.006 *$ & $\begin{array}{c}1.067 \\
(1.019-1.118)\end{array}$ \\
\hline Age at $\mathrm{BC}$ Diagnosis & 0.024 & 0.016 & 0.133 & $\begin{array}{c}1.024 \\
(1.019-1.118)\end{array}$ \\
\hline Axillary Surgery & & & 0.067 & \\
\hline None vs. SLNB & -0.704 & 0.801 & 0.379 & $\begin{array}{c}0.495 \\
(0.103-2.376)\end{array}$ \\
\hline SLNB vs. ALND & -1.268 & 0.634 & $0.045 *$ & $\begin{array}{c}0.281 \\
(0.081-0.974)\end{array}$ \\
\hline Number of LNs removed & 0.038 & 0.036 & 0.295 & $\begin{array}{c}1.038 \\
(0.968-1.114)\end{array}$ \\
\hline Radiation therapy & & & 0.171 & \\
\hline $\begin{array}{l}\text { None vs. Total breast }+ \text { subclavicular and/or axilla } \\
\text { irradiation }\end{array}$ & -0.961 & 0.515 & 0.062 & $\begin{array}{c}0.383 \\
(0.139-1.050)\end{array}$ \\
\hline $\begin{array}{l}\text { Partial or total breast irradiation vs. Total breast }+ \\
\text { subclavicular and/or axilla irradiation (RLNR) }\end{array}$ & -0.571 & 0.426 & 0.179 & $\begin{array}{c}0.565 \\
(0.245-1.301)\end{array}$ \\
\hline NSAIDs & 0.017 & 0.471 & 0.971 & $\begin{array}{c}1.017 \\
(0.404-2.559)\end{array}$ \\
\hline Calcium channel blockers & -1.078 & 0.634 & 0.089 & $\begin{array}{c}0.340 \\
(0.098-1.178)\end{array}$ \\
\hline Steroids & 20.365 & $3 \times 10^{4}$ & 0.999 & $\begin{array}{c}7 \times 10^{8} \\
--\end{array}$ \\
\hline Aspirin & 0.291 & 0.385 & 0.449 & $\begin{array}{c}1.338 \\
(0.629-2.846)\end{array}$ \\
\hline Angiotensin system inhibitors & 0.467 & 0.377 & 0.216 & $\begin{array}{c}1.596 \\
(0.762-3.343)\end{array}$ \\
\hline Hormone therapy & & & 0.173 & \\
\hline None vs. Aromatase inhibitors & -0.460 & 0.367 & 0.209 & $\begin{array}{c}0.631 \\
(0.308-1.294)\end{array}$ \\
\hline SERMs vs. Aromatase inhibitors & 0.252 & 0.392 & 0.520 & $\begin{array}{c}1.287 \\
(0.597-2.773)\end{array}$ \\
\hline Constant & -3.057 & 1.400 & 0.029 & 0.047 \\
\hline
\end{tabular}

Multivariable analysis using the full information logistic regression model. Due to sample size limitations, a selection of variables was included for analysis. BCRL: breast cancer related lymphedema; BMI: body mass index; SLNB: Sentinel lymph node biopsy; ALND: Axillary lymph node dissection; LNs: lymph nodes; RLNR: Regional lymph node radiation; NSAIDs: Nonsteroidal anti-inflammatory drugs; SERMs: selective estrogen receptor modulators.

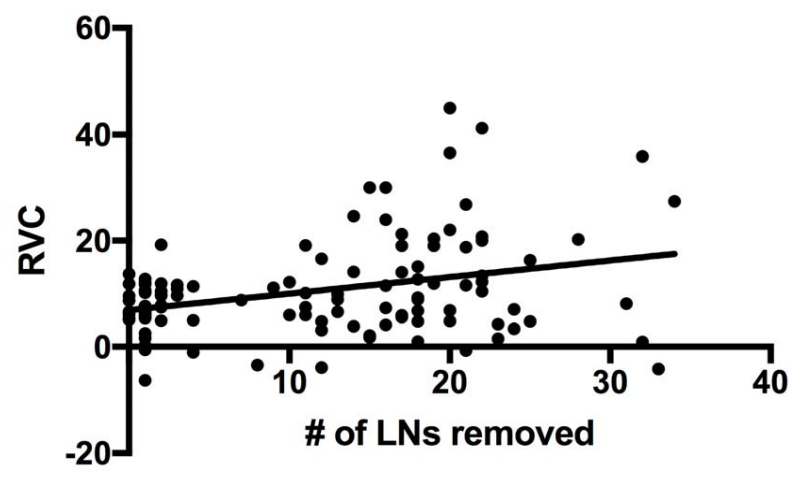

Figure 1. Linear correlation between RVC and number of lymph nodes (LNs) removed Multiple regression was performed with the arm RVC outcome and the potential risk factors from Table 1. Only the number of LNs removed was correlated to RVC and is plotted here as a univariate.

contrary to our hypothesis that ASIs would reduce risk of BCRL by inhibiting the formation of post-treatment fibrosis. As ASI treatment was only significant in the univariate analysis, this might suggest that ASI use could be related to BMI. In general, there may be an increase in prevalence of treatment resistant hypertension in obese patients, which could result in a greater likelihood of a prescription for ASIs. A power analysis (data not shown; power $=80 \%$, alpha $=0.05$ ) revealed that in order to detect a difference between ASI use and BRCL outcomes on multivariable analysis, we would need larger sample totaling 900-1000 patients given the current sample's probability of ASI use and incidence of BRCL.

The patients in our study were closely monitored for lymphedema and participated in a screening program [34]. This program is patient specific and some received aggressive treatment, including the use of compression garments, range-of-motion exercises, massage, intensive bandaging and, in select cases, additional surgery. While others have demonstrated that the number of lymph nodes removed increases the risk of lymphedema [43], our data show that the number of lymph nodes removed correlates to the severity (Figure 1). In this context, it is important for patients with many lymph nodes removed to participate in lymphedema screening programs to promote early intervention for BCRL.

In this study, we looked at hormone therapy and other groups of medications initiated before surgery and taken for at least one year postoperatively. Other medications, disease characteristics, neoadjuvant care, as well as specific prescriptions or comorbidities could not be included in the analysis due to the relatively low patient sample size. Additionally, postoperative follow-up in these patients ranged from 2- 10 years, while average time until lymphedema development in our cohort was approximately 15 months (Table 1 ). In addition to patients not experiencing disease progression at the same rate, patients are inherently in different stages of disease when analyzing RVC.

The challenge of looking retrospectively at the effect of drugs on the development and severity of lymphedema is the extensive comorbidities that are associated with the reason why the medications were prescribed 
and the effect of these comorbidities on lymphatic function. While we hypothesized ASIs would reduce the risk of BCRL, our data trended toward the opposite effect on univariate analysis. We are unable to conclude if this is due to the possibility that hypertension predisposes patients to BCRL [44], which could hypothetically outweigh any positive ASI effects in hypertensive patients. In normotensive patients, therapies with anti-fibrotic effects, such as ASIs, might be beneficial. Furthermore, ASIs may have other effects on BCRL that we did not hypothesize and may be prescribed for other medical indications than hypertension. NSAIDs are commonly prescribed for chronic inflammatory conditions. Inflammation can impair lymphatic function through production of cytokines that inhibit lymphatic pumping $[28,29,45]$. Thus, if patients with chronic inflammation are at a greater potential risk of BCRL, the use of NSAIDs might normalize this risk back to that of the general population. Our retrospective study would not be able to detect this risk reduction. Further, over the counter drug purchases might not be recorded in the medical records at all, making our dataset incomplete for NSAID use.

CCBs do not seem to have any negative effect on developing BCRL or the severity of lymphedema in our study, even though specific CCBs have been shown to reduce lymphatic function in animal experiments [33]. This indicates that there might be no contraindication for prescribing CCBs in patients at risk for developing BCRL.

\section{Conclusions}

This study represents a first attempt to observe if commonly prescribed medications can affect the risk of developing BCRL. We determined that in our sample neither anti-inflammatory, antihypertensive or hormone therapies alter the risk of developing BCRL, which all have been shown to effect lymphatic function or tissue fibrosis pre-clinically. In addition, we found that the number of lymph nodes removed correlates not only to the risk of BRCL, but also to the severity. It should be noted that for the medications, patient numbers were small, leading to an underpowered analysis for small effect sizes. Thus, further investigation with a larger cohort is warranted for these drugs.

\section{Conflict of interest}

The authors declare that they have no conflict of interest. CM did not receive any payments for his contributions.

\section{Acknowledgments}

EFJM, EMB and TPP wrote the manuscript. EFJM, EMB, CM, MNS, LWS and AGT made substantial contributions to acquiring, analyzing and interpreting the data. CM performed the statistical analyses. AGT and TPP made substantial contributions to interpreting data and on study conception and design. All authors contributed intellectually to and reviewed the manuscript.

\section{Funding}

The National Cancer Institute Federal Share of Proton Income CA059267, NIH DP2008780, NIH R01CA214913 and the Massachusetts General Hospital Executive Committee on Research ISF supported this work.

\section{Ethical Approval}

This study was approved by the Massachusetts General Hospital's Institutional Review Board.

\section{Declarations of interest}

None.

\section{References}

1. Fu MR (2014) Breast cancer-related lymphedema: Symptoms, diagnosis, risk reduction, and management. World J Clin Oncol 5: 241-247. [Crossref]

2. Tiwari P, Coriddi M, Salani R, Povoski SP (2013) Breast and gynecologic cancerrelated extremity lymphedema: a review of diagnostic modalities and management options. World J Surg Oncol 11: 237. [Crossref]

3. Ashikaga T, Krag DN, Land SR, Julian TB, Anderson SJ, et al. (2010) Morbidity results from the NSABP B-32 trial comparing sentinel lymph node dissection versus axillary dissection. J Surg Oncol 102: 111-118. [Crossref]

4. Ridner SH (2009) The psycho $\square$ social impact of lymphedema. Lymphatic research and biology 7: 109-112.

5. Warren AG, Brorson H, Borud LJ, Slavin SA (2007) Lymphedema: a comprehensive review. Ann Plast Surg 59: 464-472. [Crossref]

6. Rockson SG (2010) Causes and consequences of lymphatic disease. Ann N Y Acad Sci 1207 Suppl 1: E2-6. [Crossref]

7. Avraham T, Yan A, Zampell JC, Daluvoy SV, Haimovitz-Friedman A, et al. (2010) Radiation therapy causes loss of dermal lymphatic vessels and interferes with lymphatic function by TGF-beta1-mediated tissue fibrosis. Am J Physiol Cell Physiol 299: C589605. [Crossref]

8. Lymphatic Education \& Research Network, https://lymphaticnetwork.org/. 2019.

9. Padera TP, Meijer EF, Munn LL (2016) The Lymphatic System in Disease Processes and Cancer Progression. Annu Rev Biomed Eng 18: 125-158. [Crossref]

10. Warren LE, Punglia RS, Wong JS, Bellon JR (2014) Management of the regional lymph nodes following breast-conservation therapy for early-stage breast cancer: an evolving paradigm. Int J Radiat Oncol Biol Phys 90: 772-777. [Crossref]

11. Warren LE, Miller CL, Horick N, Skolny MN, Jammallo LS, et al. (2014) The impact of radiation therapy on the risk of lymphedema after treatment for breast cancer: a prospective cohort study. Int J Radiat Oncol Biol Phys 88: 565-571. [Crossref]

12. Whelan TJ, Olivotto IA, Parulekar WR, Ackerman I, Chua BH, et al. (2015) Regional Nodal Irradiation in Early-Stage Breast Cancer. N Engl J Med 373: 307-316. [Crossref]

13. Poortmans PM, Collette S, Kirkove C, Van Limbergen E, Budach V, et al. (2015) Internal Mammary and Medial Supraclavicular Irradiation in Breast Cancer. $N$ Engl $J$ Med 373: 317-327. [Crossref]

14. Chandra RA, Miller CL, Skolny MN, Warren LE, Horick N, et al (2015) Radiation therapy risk factors for development of lymphedema in patients treated with regional lymph node irradiation for breast cancer. International journal of radiation oncology, biology, physics 91:760-764.

15. Shah C, Arthur D, Riutta J, Whitworth P, Vicini FA (2012) Breast-cancer related lymphedema: a review of procedure-specific incidence rates, clinical assessment AIDS, treatment paradigms, and risk reduction. Breast $J$ 18: 357-361. [Crossref]

16. Kesler CT1, Kuo AH, Wong HK, Masuck DJ, Shah JL, et al. (2014) Vascular endothelial growth factor-C enhances radiosensitivity of lymphatic endothelial cells. Angiogenesis 17: 419-427. [Crossref]

17. Martin M1, Lefaix J, Delanian S (2000) TGF-betal and radiation fibrosis: a master switch and a specific therapeutic target? Int J Radiat Oncol Biol Phys 47: 277-290. [Crossref]

18. Martin M, Lefaix JL, Pinton P, Crechet F, Daburon F (1993) Temporal modulation of TGF-beta 1 and beta-actin gene expression in pig skin and muscular fibrosis after ionizing radiation. Radiat Res 134: 63-70. [Crossref]

19. Lynch LL, Mendez U, Waller AB, Gillette AA, Guillory RJ 2nd, et al. (2015) Fibrosis worsens chronic lymphedema in rodent tissues. Am J Physiol Heart Circ Physiol 308: H1229-1236. [Crossref]

20. Clavin NW, Avraham T, Fernandez J, Daluvoy SV, Soares MA, et al. (2008) TGFbeta1 is a negative regulator of lymphatic regeneration during wound repair. $\mathrm{Am} \mathrm{J}$ Physiol Heart Circ Physiol 295: H2113-2127. [Crossref]

21. Oka M, Iwata C, Suzuki HI, Kiyono K, Morishita Y, et al. (2008) Inhibition of endogenous TGF-beta signaling enhances lymphangiogenesis. Blood 111: 4571-4579. [Crossref]

22. el-Agroudy AE, Hassan NA, Foda MA, Ismail AM, el-Sawy EA, et al. (2003) Effect of angiotensin II receptor blocker on plasma levels of TGF-beta 1 and interstitial fibrosis in hypertensive kidney transplant patients. Am J Nephrol 23: 300-306. [Crossref]

23. Godugu C, Patel AR, Marepally S, Doddapaneni R, Sachdeva MS, et al. (2013) Effect of telmisartan on triple negative breast cancer (TNBC) and lung cancer tumor progression and intratumoral distribution of nanoparticles. Cancer Research 73: 8 . 
24. Molteni A, Wolfe LF, Ward WF, Ts'ao CH, Molteni LB, et al. (2007) Effect of an angiotensin II receptor blocker and two angiotensin converting enzyme inhibitors on transforming growth factor-beta (TGF-beta) and alpha-actomyosin (alpha SMA), important mediators of radiation-induced pneumopathy and lung fibrosis. Curr Pharm Des 13: 1307-1316. [Crossref]

25. Okazaki M, Fushida S, Harada S, Tsukada T, Kinoshita J, et al. (2014) The angiotensin II type 1 receptor blocker candesartan suppresses proliferation and fibrosis in gastric cancer. Cancer Lett 355: 46-53. [Crossref]

26. Chauhan VP, Martin JD, Liu H, Lacorre DA, Jain SR, et al. (2013) Angiotensin inhibition enhances drug delivery and potentiates chemotherapy by decompressing tumour blood vessels. Nat Commun 4: 2516. [Crossref]

27. Katler E, Weissmann G (1977) Steroids, aspirin, and inflammation. Inflammation 2: 295-307. [Crossref]

28. Al-Kofahi M, Becker F, Gavins FN, Woolard MD (2015) IL-1 $\beta$ reduces tonic contraction of mesenteric lymphatic muscle cells, with the involvement of cycloxygenase-2 and prostaglandin E2. Br J Pharmacol 172: 4038-4051. [Crossref]

29. von der Weid PY, Muthuchamy M (2010) Regulatory mechanisms in lymphatic vessel contraction under normal and inflammatory conditions. Pathophysiology 17: 263-276. [Crossref]

30. Chambers JC1, McGovern K (2005) Tamoxifen for retroperitoneal fibrosis. Palliat Med 19: 163-164. [Crossref]

31. van der Bilt FE, Hendriksz TR, van der Meijden WA, Brilman LG, van Bommel EF (2016) Outcome in patients with idiopathic retroperitoneal fibrosis treated with corticosteroid or tamoxifen monotherapy. Clin Kidney J 9: 184-191. [Crossref]

32. Vaglio A, Palmisano A, Alberici F, Maggiore U, Ferretti S, et al. (2011) Prednisone versus tamoxifen in patients with idiopathic retroperitoneal fibrosis: an open-label randomised controlled trial. Lancet 378: 338-346. [Crossref]

33. Lee S, Roizes S, von der Weid PY (2014) Distinct roles of L- and T-type voltagedependent $\mathrm{Ca} 2+$ channels in regulation of lymphatic vessel contractile activity. $J$ Physiol 592: 5409-5427. [Crossref]

34. Brunelle C, Skolny M, Ferguson C, Swaroop M, O'Toole J, et al. (2015) Establishing and sustaining a prospective screening program for breast cancer-related lymphedema at the massachusetts general hospital: lessons learned. J Pers Med 5: 153-164. [Crossref]
35. Ancukiewicz M, Russell TA, Otoole J, Specht M, Singer M, et al. (2011) Standardized method for quantification of developing lymphedema in patients treated for breast cancer. Int J Radiat Oncol Biol Phys 79: 1436-1443. [Crossref]

36. Mansel RE, Fallowfield L, Kissin M, Goyal A, Newcombe RG, et al. (2006) Randomized multicenter trial of sentinel node biopsy versus standard axillary treatment in operable breast cancer: the ALMANAC Trial. J Natl Cancer Inst 98: 599-609. [Crossref]

37. Del Bianco P, Zavagno G, Burelli P, Scalco G, Barutta L, et al. (2008) Morbidity comparison of sentinel lymph node biopsy versus conventional axillary lymph node dissection for breast cancer patients: results of the sentinella-GIVOM Italian randomised clinical trial. Eur J Surg Oncol 34: 508-513. [Crossref]

38. Lucci A, McCall LM, Beitsch PD, Whitworth PW, Reintgen DS, et al. (2007) Surgical complications associated with sentinel lymph node dissection (SLND) plus axillary lymph node dissection compared with SLND alone in the American College of Surgeons Oncology Group Trial Z0011. J Clin Oncol 25: 3657-3663. [Crossref]

39. Werner RS, McCormick B, Petrek J, Cox L, Cirrincione C, et al. (1991) Arm edema in conservatively managed breast cancer: obesity is a major predictive factor. Radiology 180: 177-184. [Crossref]

40. Soran A, D'Angelo G, Begovic M, Ardic F, Harlak A, et al. (2006) Breast cancerrelated lymphedema--what are the significant predictors and how they affect the severity of lymphedema? Breast $J$ 12: 536-543. [Crossref]

41. Clark B, Sitzia J, Harlow W (2005) Incidence and risk of arm oedema following treatment for breast cancer: a three-year follow-up study. QJM 98: 343-348. [Crossref]

42. Helyer LK, Varnic M, Le LW, Leong W, McCready D (2010) Obesity is a risk factor for developing postoperative lymphedema in breast cancer patients. Breast $J$ 16: 48-54. [Crossref]

43. Goldberg JI, Riedel ER, Morrow M, Van Zee KJ (2011) Morbidity of sentinel node biopsy: relationship between number of excised lymph nodes and patient perceptions of lymphedema. Ann Surg Oncol 18: 2866-2872. [Crossref]

44. Rockson SG1 (1998) Precipitating factors in lymphedema: myths and realities. Cancer 83: 2814-2816. [Crossref]

45. Liao S, Cheng G, Conner DA, Huang Y, Kucherlapati RS, et al. (2011) Impaired lymphatic contraction associated with immunosuppression. Proc Natl Acad Sci U S A 108: 18784-18789. [Crossref]

Copyright: (C2020 Meijer EFJ. This is an open-access article distributed under the terms of the Creative Commons Attribution License, which permits unrestricted use, distribution, and reproduction in any medium, provided the original author and source are credited. 